\title{
Imagem social do design: um estudo sobre como designers e não- designers descrevem o design
}

\author{
Meyer, Guilherme Corrêa \\ UNISINOS \\ gcmeyer@unisinos.br \\ Scaletsky, Celso Carnos \\ UNISINOS \\ celsocs@unisinos.br \\ Vaccaro, Guilherme \\ UNISINOS \\ guilhermevaccaro@gmail.com \\ Azevedo, Débora \\ UNISINOS \\ deboraazevedo1808@gmail.com
}

\begin{abstract}
Resumo: Este artigo investiga a maneira como o design é percebido por profissionais da área e pelo público em geral. No estudo foram aplicados 136 questionários para designers $(\mathrm{N}=63)$ e não-designers $(\mathrm{N}=73)$. Uma pergunta aberta pedia para que os entrevistados apresentassem sua definição de design. As respostas foram analisadas mediante a técnica de Análise de Conteúdo. As definições relacionaram o design ao processo (método e uso de ferramentas), às qualidades e características dos produtos (modo de produção, aspectos técnicos, estéticos e simbólicos) e aos efeitos gerais da atividade (contextos em que atua, modo como opera). Esta pesquisa concentra-se nas semelhanças e divergências entre os significados que designers e não-designers associam ao design, e assim reflete a respeito da imagem social construída sobre a área.
\end{abstract}

Palavras-chave: Design, Imagem social, não-designers.

\section{INTRODUÇÃO}

O estudo do design como atividade profissional é recente. As primeiras reflexões sobre a atividade remontam a 1920, ainda que tais estudos somente foram ganhando corpo mais recentemente. Tal processo é marcado por esforços deliberados empreendidos no âmbito acadêmico e em meio às práticas profissionais. Como aconteceu com muitas outras áreas em formação, essa força conjunta ocupou-se da 
tarefa de delimitar as abrangências da área, de identificar as práticas profissionais daqueles que se destacavam na época, de determinar os papeis e as competências desses profissionais, para assim distinguir a atividade de outras que the fossem próximas. Tratou-se, assim, de um exercício de demarcação criterioso do campo. Não nos causará estranhamento, portanto, a constatação de que os primeiros ensaios sobre design procuravam descrever diligentemente um conjunto de 'normas e restrições' que deixassem claro 'o que era design' e 'quem era designer' (Cardoso, 2008 , p. 19). O exercício foi de certa forma realizado, daí a frequência com que as pessoas parecem associar o design a produção em série e ao processo industrial, à funcionalidade técnica e ao bom desempenho físico dos produtos.

Destacar os problemas dessa delimitação (que depois se revelaria falha) é incorrer em anacronismo, pois para isso acaba-se esquecendo dos elementos do contexto em questão. Quando o design era 'inventado' entre meados do século XVIII e o término do século XIX, 'ser designer' era atender às expectativas que vinham do surgimento das fábricas. Naquele momento, as mudanças nas mais amplas esferas sociais, ocasionadas em parte pelo incremento hercúleo das tecnologias produtivas e dos sistemas de distribuição e transporte, fez com que os alcances do consumo se espalhassem por todos os lados. Essa disseminação de bens de consumo, mal ou bem, serviu de estímulo para a formalização de um profissional atento a configuração dessas mercadorias. Assim, as atividades de projetação (já desenvolvidas há muito em outros âmbitos, como salientou Forty [2007]), passaram a ocupar destacada importância no meio industrial. Desde então, as transformações que o profissional foi realizando foram incisivas e de difícil apreciação. Ainda assim, alguns autores as sintetizaram mesmo que genericamente:

\begin{abstract}
"Os primeiros designers (...) tenderam a emergir de dentro do processo produtivo e eram aqueles operários promovidos por quesitos de experiência ou habilidade a uma posição de controle e concepção, em relação às outras etapas da divisão de trabalho. A transformação dessa figura de origens operárias em um profissional liberal, divorciado da experiência produtiva de uma indústria especifica e habilitado a gerar projetos de maneira genérica, corresponde a um longo processo evolutivo que teve seu início na organização das primeiras escolas de design no século 19 e que continuou com a institucionalização do campo ao longo do século 20" (Cardoso, 2008, p.22).
\end{abstract}

Esse caráter transformativo, que acompanhou o designer desde sua origem operária, parece ainda se revelar presente nos dias atuais. Naturalmente, as mudanças tornam-se mais ou menos intensas em função dos cenários em que estão inseridas. Não nos serão desconhecidas aqui as preleções sobre a maneira ágil, efusiva e radical com que as organizações sociais, políticas e econômicas vêm se modificando nas últimas décadas (Castells, 2009). Por exemplo, o paradigma da produção industrial de 1960 sugeria a produção em massa como ideal (muitos produtos para todos), inserido em um contexto de demanda maior que a oferta e com limitações tecnológicas e de percepção que moldavam a capacidade de redução de custos à produção de grandes volumes. Hoje, em um contexto de maior competição e atribuição de valor a um conjunto mais complexo de quesitos, percebemo-nos em um quadro em que a indústria parece inclinar-se aos modelos de produção flexível, que atenda às exigentes demandas por singularização e diferenciação. Em um recorte de tempo mais preciso, 
lembraremos que nos anos 1980 quase não existiam computadores e as pessoas construíam suas redes sociais em ambientes físicos bem delimitados. Atualmente, pela maneira constante através da qual a internet nos conecta, as relações como que se desvencilham de quaisquer atribuições de tempo ou espaço. As próprias definições do campo sofreram alterações sistemáticas de surpreendente intensidade, passando a revelar atenções com o usuário ou o contexto que antes eram preteridos (Cara, 2010). Antes de buscarmos por outros casos, cremos ser possível pressupor que os aspectos que antes assinalavam a legitimidade profissional no design tenham se transformado junto às dinâmicas volúveis de nossa sociedade.

Nesse cenário, cabe destacar os problemas referentes às definições do campo. Em parte tais problemas explicam-se pelo caráter ubíquo do design. Afirmações como tudo é design (Hjelm, 2005), o design é onipresente (Chandrasegaran et al., 2013) ou design é uma habilidade humana natural (Cross 1999), que parece figurar em alguns estudos da área, contribuem para as confusões relativas a percepção do público sobre o que é design e, consequentemente, sobre o que o designer faz. Afinal, se algo é associado a tudo, como distinguir-lhe o particular?

A falta de esclarecimentos nesse âmbito parece resultar também do caráter interdisciplinar da área. Afinal, se o design é uma disciplina integrativa localizada na interseção de diversos outros campo (Friedman, 2003, p. 509) quais seus materiais próprios? Sob tal ponto de vista os limites que separam o design de áreas vizinhas tornam-se tênues e confusos. Além disso, os estudos etimológicos do design revelam uma ambiguidade latente. Quando o tomamos por sua carga sintática, o veremos funcionar a um só tempo como verbo e substantivo (Flusser, 2007). Ou seja, design refere-se a um processo (uma ação) assim como se refere ao resultado de algo (um produto).

Pensando nesse contexto de transformações incisivas no campo, assim como nas imprecisões que se espalham sobre as definições do design, somos levados a supor que (1) o designer vem modificando seus domínios de atuação (operando, por exemplo, em setores administrativos ou estratégicos de organizações [Zurlo, 2010]); (2) o modo como o designer age profissionalmente igualmente transforma-se (seus atributos, competências, seu papel passa a ser outro), tais eventos fazem com que as possibilidade de atuação para um designer em formação alarguem-se de tal forma que (3) jovens e adultos, representantes de organizações públicas ou privadas, o público de forma geral não consiga abranger as importâncias do design. Assim, dessa proposição inicial, interessa-nos entender o tipo de imagem que o público geral constrói sobre o design. Além disso, procura-se investigar aqui a relação entre a imagem social que as pessoas fazem do design, e a forma como os próprios designers percebem sua atividade. Tal emparelhamento é uma forma de se pensar as distâncias que parecem separar o que o design faz das expectativas que dele se têm, e assim dar mais um passo nas discussões sobre as definições do campo. Neste sentido, este estudo investiga, por meio de um levantamento, a maneira como o design é percebido por profissionais da área e pelo público em geral.

\section{Representações sociais}

As imagens que um público constrói sobre um evento qualquer remete à noção de representações sociais. O conceito de representações sociais é definido por Moscovici (2003) como um conjunto de classes gerais de ideias e crenças utilizadas 
coletivamente para se estabelecer uma espécie de ordem social. As representações sociais interessam-se pelas dinâmicas através das quais as pessoas constroem sentido em relação a algo. Tais representações referem-se a uma espécie de conhecimento do senso comum, elaborado nas interações sociais e compartilhado pelos indivíduos de um grupo social (Moscovici, 2001).

Uma série de estudos vem mostrando o papel das representações sociais nas investigações empíricas sobre o conhecimento público (Farr, 1994). As pesquisas sobre as representações sociais da tecnologia, por exemplo, mostram que o público geral frequentemente possui baixos índices de entendimento sobre tecnologia (Miller, 2000; Eurobarometer, 2001). Outros estudos falam de uma proposição que parece figurar entre os designers: a ideia de que os não-designers não sabem o que é design. Assim entre os designers revelam-se preleções como: "as pessoas não sabem o que é design, não conhecem o valor do design, não são capazes de avaliar a qualidade de um trabalho ou a competência do profissional, e tampouco imaginam tudo o que está por trás de um projeto bem feito" (Meyer, 2011, p. 30). Esse discurso pode ser entendido como um mecanismo de legitimação e distinção profissional, pois "sempre que um grupo toma consciência de sua identidade profissional, passa a se diferenciar pela inclusão de uns e pela exclusão de outros, e uma maneira muito eficaz de justificar essa separação é através da construção de genealogias históricas que determinem os herdeiros legítimos de uma tradição relegando quem fica de fora a ilegitimidade. (Cardoso, 1998, p. 18-19).

Apesar desse aparente distanciamento entre o público especialista e leigo, entende-se que as opiniões formadas pelo público geral sobre uma área são compostas de fragmentos de grande variedade e fartura, pois são meios de se tomar a opinião de diversos outros atores sociais, como a mídia de massa, a indústria, as organizações, os setores regulatórios (Christidou, et al., 2004, p. 347). Ainda que o produto das representações sociais do público geral por vezes seja associado a um tipo de saber ingênuo, ele constitui um conjunto tão legítimo quanto o do saber científico. Investigá-lo é um meio de se alcançar esclarecimentos sobre a importância social daquilo que se trata, orientar condutas, intervir no processo de difusão e assimilação de conhecimento, na definição das identidades pessoais e sociais, na expressão dos grupos e nas transformações sociais (Christidou, et al., 2004).

Desta forma, as representações sociais são uma forma de conhecimento socialmente elaborado e compartilhado, que se utilizam de aspectos relacionados a normas, crenças, valores, atitudes, opiniões de um dado grupo sobre algo e constituem um tipo de realidade criada pelo grupo de informantes (Jodelet, 2001, p. 22). Os estudos de representações sociais são uma forma de descrever, interpretar e explicar formas, processos e funcionamentos desses elementos.

\section{Método}

O estudo desenvolvido é exploratório e baseia-se em um instrumento formado por duas questões abertas, além de dados demográficos (proximidade com a área de design, gênero e faixa etária). A primeira questão aberta solicitava que o respondente escrevesse 5 palavras que melhor definissem design para si. A segunda questão solicitava que o respondente escrevesse uma definição própria para design. Mais especificamente, a segunda pergunta era: na sua opinião, o que é design? As respostas não poderiam exceder 120 caracteres. Neste artigo, utilizaremos somente das 
respostas da segunda questão aberta.

$O$ instrumento foi publicado em uma plataforma de respostas online (www.surveymonkey.com). A coleta foi realizada por meio de contatos eletrônicos. Para acessar designers foi enviado um e-mail para 256 designers cadastrados na Associação dos Profissionais em Design do Rio Grande do Sul (APDesign). Para acessar o público em geral a pesquisa foi divulgada por e-mail e em redes sociais, solicitando a participação do destinatário e também que a mensagem fosse repassada adiante, por meio da estratégia de coleta "bola de neve" (snowball).

A coleta foi realizada em duas ondas. 15 dias após o envio da primeira onda, uma nova solicitação foi enviada para os que não haviam respondido a pesquisa. $O$ link ficou ativo por 30 dias e depois desse período as respostas foram analisadas.

Das 136 respostas obtidas válidas, 46.3\% ( $N=63)$ vinham de respondentes que se declararam profissionais que atuavam em atividades de design, e 53.7\% ( $N=73)$ que se declararam sem relação com atividades de design. Para efeitos gerais, nomeamos designers os respondentes do primeiro grupo, e não-designers os respondentes do segundo grupo.

A análise das respostas considerou inicialmente todos os respondentes (designers e não-designers) num mesmo grupo. Esse primeiro estágio de trabalhos serviu de teste para avaliarmos as dinâmicas do grupo de pesquisa sobre a aplicação da técnica de análise escolhida, descrita a seguir. Após esse estágio, foram feitas análises separadas, de uma lado as definições dos designers e de outro a dos nãodesigners. Análises descritivas e de classificação dos dados foram realizadas com o suporte do software SPSS Statistics. A análise das questões, propriamente dita, foi realizada pela técnica de Análise de Conteúdo (Moraes, 1999; Krippendorff, 2013).

Para Krippendorff (2013, p. 24), a Análise de Conteúdo é uma técnica de pesquisa interessada em alcançar inferências válidas e replicáveis de textos. A técnica costuma apresentar estágios de alguma forma definidos. Nesta pesquisa optamos pelo processo descrito por Moraes (1999). Tal envolve: (1) Preparação das informações, em que se (a) identificam e (b) codificam as amostras de informação a serem analisadas; (2) Unitarização ou transformação do conteúdo em unidades, que passa pela (a) definição e (b) isolamento das unidades de análise, bem como pela definição das unidades de contexto; (3) Categorização ou classificação das unidades em categorias, de modo que sejam elas válidas, exaustivas e homogêneas; (4) Descrição, em que se comunica o material das categorias e; (5) Interpretação, interessada uma compreensão mais aprofundada do conteúdo das mensagens.

Em meio ao processo de análise, as respostas foram impressas em folhas A4. Inicialmente quatro duplas de pesquisadores trabalharam separadamente, identificando as unidades de análise e as categorias. As categorias identificadas foram então dispostas em um quadro branco comum. A figura 1 ilustra as categorias emparelhadas. Foi feita uma discussão entre os pesquisadores de forma a identificar analogias e discrepâncias entre as categorias listadas. Algumas categorias foram eliminadas ou modificadas pois sugeriam repetição entre si, desajuste em relação aos dados analisados, ou algum tipo de inadequação. Assim, alcançaram-se 3 categorias em relação a maneira como designers e não-designers definiam o design, divididas em 8 subcategorias. 

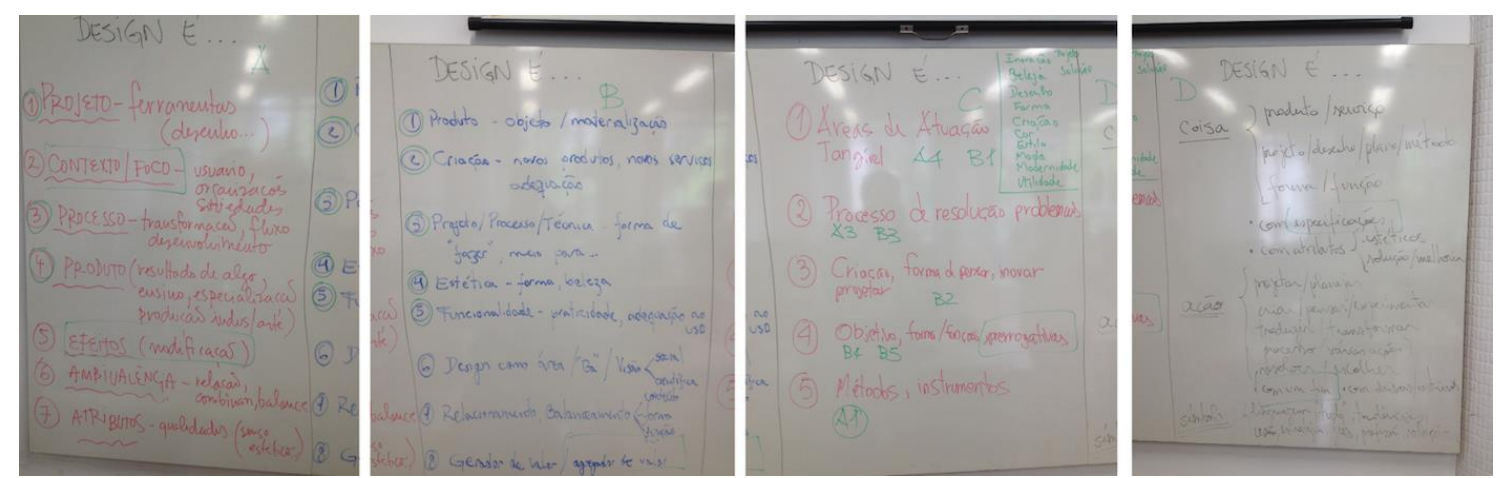

Figura 1 - Categorias em discussão

Fonte: Elaborado pelos autores, com base na pesquisa realizada

\section{Apresentação dos resultados}

Aqui apresentaremos a análise sobre as definições coletadas. Os quadros 1 e 2 distribuem a análise em três eixos principais: categorias (C), subcategorias (SC) e unidades de análise, subsidiando a análise das semelhanças e divergências entre percepções desses dois grupos, apoiados em princípios gerais apontados pelos estudos da área.

As definições escritas foram organizadas pela proximidade semântica das unidades de análise investigadas. As unidades de análise repetidas ou redundantes foram suprimidas sempre que tal operação não trouxesse prejuízos para a análise. As decisões sobre essas escolhas foram realizadas em seções específicas entre os pesquisadores. Descreveremos as categorias para depois discutir seus materiais. 0 resultado selecionado para representar a visão de designers é apresentado no Quadro 1 e o referente à visão de não-designers no Quadro 2.

\begin{tabular}{|c|c|c|}
\hline C & SC & Unidades de análise \\
\hline \multirow{3}{*}{ 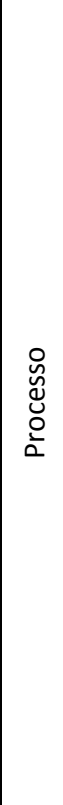 } & 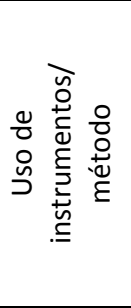 & $\begin{array}{l}\text { "(...) ferramenta de poder transformador" } \\
\text { "(...) com embasamento em pesquisas e análises e conhecimento nas etapas principais do } \\
\text { processo" } \\
\text { "(...) através de métodos e pesquisas aplicados. É muito mais do que desenhos e croquis(...)" } \\
\text { "É um conjunto de processos e metodologias(...)" } \\
\text { "Metodologia que ajusta função e estética" } \\
\text { "É um processo de pesquisa, ideias, conceitos projeto e solução (...)" } \\
\text { "Uma atividade que une projeto, criatividade e método(...)" }\end{array}$ \\
\hline & 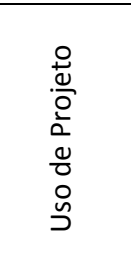 & $\begin{array}{l}\text { “(...) algo pensado e projetado" } \\
\text { "(...) desenvolvimento de projeto" } \\
\text { “(...) projeto inovador" } \\
\text { "é projetar, é criar (...)" } \\
\text { “(...) forma de pensar o mundo por meio do desenvolvimento de projetos" } \\
\text { "Design é projeto" } \\
\text { "Basicamente projeto integrado" }\end{array}$ \\
\hline & 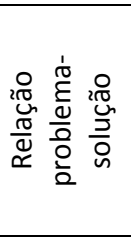 & $\begin{array}{l}\text { “(...) resolver problemas (...)" } \\
\text { “(...) melhor escolha possível dentro de uma 'infinita' gama de possibilidades" } \\
\text { "Equacionamento simultâneo de fatores (...) para a solução de uma necessidade (...)" } \\
\text { "É a atividade de pensar em soluções para os problemas da atualidade" } \\
\text { "É a metodologia aplicada na percepção de um problema e busca de soluções (...) } \\
\text { “(...) desenvolver novos produtos através da resolução de problemas" }\end{array}$ \\
\hline 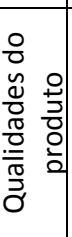 & 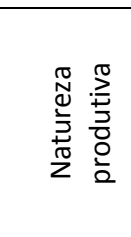 & $\begin{array}{l}\text { “(...) gráfico ou produto” } \\
\text { “(..) produtos ou serviços" } \\
\text { “(...) desenvolvimento de produto" } \\
\text { “(...) gerar produtos ou serviços (...)” } \\
\text { “(..) seja na área de produto, gráfico, comunicação, ambiental ou serviços”. } \\
\text { “(...) todo produto produzido em série seja ele industrial ou artesanal”(...) }\end{array}$ \\
\hline
\end{tabular}




\begin{tabular}{|c|c|c|}
\hline & 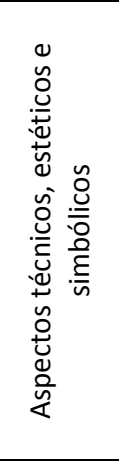 & 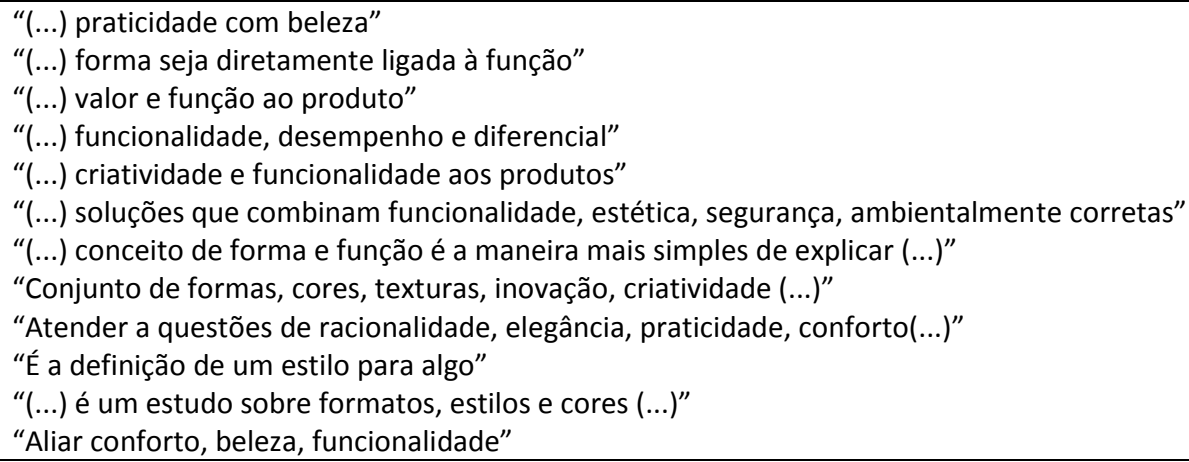 \\
\hline \multirow[b]{2}{*}{ 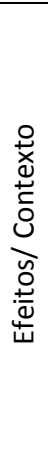 } & 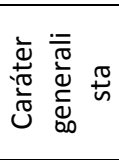 & $\begin{array}{l}\text { "(...) está em toda parte" } \\
\text { "Obter o melhor de qualquer coisa (...)" } \\
\text { "Tudo" } \\
\text { "É algo que causa impacto (...)" }\end{array}$ \\
\hline & 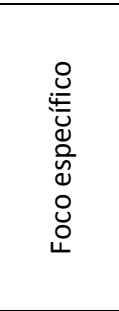 & $\begin{array}{l}\text { “(...) poder transformador para a sociedade(...)" } \\
\text { “(...) auxiliar no dia-a-dia das pessoas" } \\
\text { “(...) foco no usuário (...)" } \\
\text { “(...) é projetar para melhoria do produto" } \\
\text { “(...) produtos e serviços que facilitem a vida das pessoas" } \\
\text { “(...) para (...) necessidades ou problema das pessoas e sociedade como um todo" } \\
\text { “(..) tem que atender a forma comercial (...)” } \\
\text { “(...) pensar na relação do homem com 'as coisas"” }\end{array}$ \\
\hline
\end{tabular}

Quadro 1 - Definições de designers sobre “O que é design?”.

Fonte: Elaborado pelos autores, com base na pesquisa realizada.

\begin{tabular}{|c|c|c|}
\hline $\mathbf{C}$ & SC & $\begin{array}{c}\text { Unidades de análise } \\
\end{array}$ \\
\hline \multirow{4}{*}{ 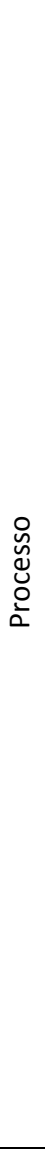 } & 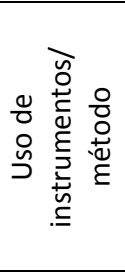 & $\begin{array}{l}\text { "É o modelo de algo, de um produto ou objeto" } \\
\text { "Forma, desenho, objeto" } \\
\text { "Algo criado para mostrar o melhor entendimento daquilo que quero mostrar" } \\
\text { "(...) é um trabalho desenvolvido através de uma pesquisa x (...) } \\
\text { "É o desenho de como será conduzido o estudo ou projeto" } \\
\text { "É o desenho de algum produto ou objeto" } \\
\text { "(...) me lembra um pouco papéis rabiscados com ideias" }\end{array}$ \\
\hline & $\begin{array}{l}\frac{0}{.0} \\
\frac{1}{0} \\
\frac{0}{2} \\
\frac{0}{0} \\
0 \\
\stackrel{0}{D}\end{array}$ & $\begin{array}{l}\text { "Projetar (...)" } \\
\text { "É forma como engenheiros, projetistas, arquitetos, desenvolvem seus projetos (...) feito de forma } \\
\text { planejada" } \\
\text { "está relacionado com um melhor uso e planejamento dos produtos" } \\
\text { "É a elaboração e especificação de um projeto" } \\
\text { "(...) área ligada ao projeto" }\end{array}$ \\
\hline & 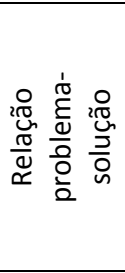 & $\begin{array}{l}\text { "É o processo de criação (...) que atenda a necessidade (...)" } \\
\text { "fazer um sonho realidade (...)" } \\
\text { "Design é sentir os problemas de uma sociedade e tentar descobrir caminhos para resolvê-los" } \\
\text { "É uma abordagem "holística" de um problema (...)É uma arte no sentido de manipular a forma na } \\
\text { solução do problema de forma eficiente" } \\
\text { "(...) desenvolver soluções de forma inovadora" } \\
\text { "(...) solução multidisciplinar para problemas" }\end{array}$ \\
\hline & 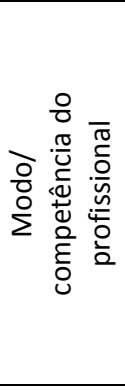 & $\begin{array}{l}\text { "Design é um jeito diferente de pensar (...) um jeito novo (...)" } \\
\text { "Design é a mais pura forma de colocar pra fora a criatividade, o desejo, a paixão" } \\
\text { "(...) design é a arte de criar algo diferente" } \\
\text { "transformar uma ideia em algo visual que transmita a mensagem" } \\
\text { "juntando com um pouco de desempenho e talento, e misturado com a criatividade } \\
\text { "maneira de apresentar um produto (...)" } \\
\text { "Design é uma forma de expressar um pensamento, um conceito na prática" } \\
\text { "(...) criação com ideias praticas, harmônicas e com uma visão artística" } \\
\text { "(...) maneira de pensar a forma" } \\
\text { "um "modelo mental" que busca quebrar conceitos de negócio usados até agora" }\end{array}$ \\
\hline $\begin{array}{l}\text { 움 } \\
y \\
\frac{y}{0}\end{array}$ & 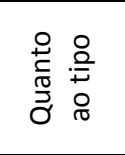 & $\begin{array}{l}\text { “(...) produtos e serviços" } \\
\text { "(...) objeto" } \\
\text { “(...) produto, serviço ou processo" } \\
\text { “(..) é a criação de um ambiente e/ou objeto" }\end{array}$ \\
\hline
\end{tabular}




\begin{tabular}{|c|c|c|}
\hline & & $\begin{array}{l}\text { "(...) produtos e/ou materiais de comunicação" } \\
\text { “(..) seja gráfico, físico, experiência” } \\
\text { "(...) que se empregam em qualquer coisa, desde móveis, arquitetura, roupas” }\end{array}$ \\
\hline & $\stackrel{n}{z}$ & $\begin{array}{l}\text { "(...) que pode vir a ser industrializado posteriormente" } \\
\text { “(...) desenvolvimento de objeto ou solução a serem repetidos industrialmente" }\end{array}$ \\
\hline & 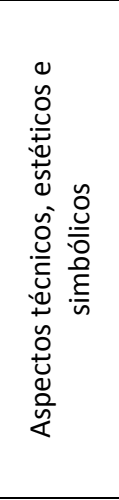 & $\begin{array}{l}\text { “(...) baseado na forma e função, não só estética" } \\
\text { "(...) formas diferenciadas para as coisas" } \\
\text { "para que os torne (os projetos), belos, arrojados, com cores que se adequam" } \\
\text { "forma, rótulo, imagens e detalhes de um produto" } \\
\text { "Criação de algo funcional (...)" } \\
\text { "Forma (...)" } \\
\text { "(...) objetos que remetem a beleza e o estilo" } \\
\text { "(...) criar coisas que funcionem e sejam bonitas" } \\
\text { "Preocupação com a forma e/ou aparência de diferentes produtos" } \\
\text { "Melhorias físicas em um produto" } \\
\text { "algo mais confortável ou mais atraente" } \\
\text { "(...) para tornar algo atrativo e bem posicionado" “ } \\
\text { "(...) algo bonito e novo" }\end{array}$ \\
\hline & 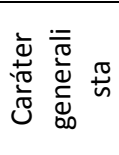 & $\begin{array}{l}\text { "Expressar tudo o que existe por dentro" } \\
\text { "É como o ambiente (ou qualquer coisa) se apresenta (...) } \\
\text { "adequação dos objetos à visão de mundo" } \\
\text { "(...) são formas, cores, modelos, arranjos (...)" }\end{array}$ \\
\hline 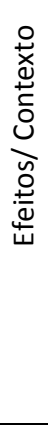 & 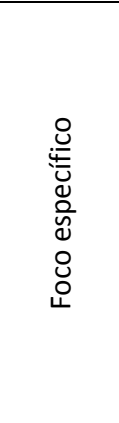 & $\begin{array}{l}\text { "(...) atender as necessidades do consumidor" } \\
\text { "Criação e desenvolvimento de novos produtos" } \\
\text { “(...) desenvolvimento de soluções inovadoras para produtos" } \\
\text { “(...) que atenda a necessidade de uma pessoa/ambiente" } \\
\text { "(...) que facilite a vida das pessoas" } \\
\text { "É a forma e o jeito de como um objeto interage com o ambiente" } \\
\text { “(...) para a sociedade e para o consumidor" } \\
\text { “(..) ajustando necessidades de algo nível destacadas pelo cliente" } \\
\text { “(...) vistos objetivos estabelecidos" } \\
\text { "São tendências que vão e vêm conforme o passar do tempo" } \\
\text { “(...)para determinado conceito e publico alvo" }\end{array}$ \\
\hline
\end{tabular}

Quadro 2 - Definições de não-designers sobre “O que é design?”.

Fonte: Elaborado pelos autores, com base na pesquisa realizada.

\subsection{Definindo o design pelo processo}

$O$ conceito de processo envolve sempre transformação (estado A em estado B). Esta categoria ocupa-se das falas que sugeriam algum tipo de movimento relacionado à atividade de design. Mais particularmente, compreende ideias manifestadas pelos informantes sobre as maneiras pelas quais se age no design. Suas subcategorias são Uso de instrumentos/método; Uso de Projeto; Relação Problema-Solução. As definições manifestadas por não-designers sugerem ainda um quarto nível de subcategoria (não presente nas definições de designers), que nomeamos Modo/competência do profissional.

A subcategoria Uso de Instrumento/método reúne ideias relacionadas à utilização de métodos e técnicas como meio para caracterizar o design. Entre os textos dos designers destacam-se passagens que ressaltam envolver o design um "conjunto de processos e metodologias", "métodos e pesquisa aplicados", uso de "ferramentas". As definições de não-designers destacam nessa subcategoria as ideias de "modelo", "desenho" e "pesquisa".

Definir o design quanto ao Uso de projeto significa manifestar na definição o vínculo entre design e projeto. Os designers definem o design dessa maneira em passagens como "algo pensado e projetado", ou "design é projeto". Os não-designers optam por ideias aparentemente equivalentes, ressaltando: "(o design é) área ligada ao projeto", "(design é) elaboração e especificação de um projeto". 
Mostrou-se presente também como eixo de algumas definições a ideia de que o design define-se pela forma como relaciona problema e solução. Entre os designers percebe-se ideias como: "resolver problemas", "atividade de pensar em soluções para os problemas da atualidade". Os não-designers manifestaram: "fazer um sonho em realidade", "É uma arte no sentido de manipular a forma na solução do problema" ou "solução multidisciplinar para problemas".

Uma quarta subcategoria emergiu da análise de definições de não-designers: Modo/competência do profissional. Aqui define-se o design pelo modo particular como atua o profissional, o que envolve as competências e habilidades do profissional. Algumas passagens esclarecem: "um jeito diferente de pensar (...) um jeito novo", "maneira de apresentar um produto", "maneira de pensar a forma", "um modelo mental".

\subsection{Definindo o design pelas Qualidades do produto}

Definir o design pela perspectiva do produto significa pensar nas qualidades do produto como meio de esclarecer-se as características da atividade. A palavra produto poderia ser substituída por outra mais adequada, como artefato. Afinal, produto refere-se a um tipo de artefato particular que habita os interiores das fábricas (Krippendorff, 2006), enquanto artefato envolve outros âmbitos, como bens e serviços, por exemplo. Optamos por manter o termo produto pois foi o termo adotado pelos informantes.

Ambos os grupos de informantes pensaram o design pela variedade de produtos a que se dedica. Os tipos de produto manifestam-se em fragmentos de definições como estas: "produto, gráfico, comunicação, ambiental ou serviços", "(...) se empregam em qualquer coisa, desde móveis, arquitetura, roupas", "ambiente e/ou objeto", ou ainda "gráfico, físico, experiência".

Os produtos também definem-se por meio de sua Natureza produtiva, sendo industriais, artesanais; ou pelo tamanho da escala ("produzido em série, seja ele industrial ou artesanal", "repetidos industrialmente").

A terceira subcategoria esboçada neste campo diz respeito aos Aspectos técnicos, estéticos e simbólicos dos produtos. Aqui os informantes definem o design por meio de qualidades variadas dos produtos.

Os aspectos técnicos dizem respeito a propriedades práticas do produto, relacionadas a desempenho, performance, componentes físicos. Os designers destacaram palavras como: "praticidade", "função", "segurança", "ambientalmente corretas", "texturas", "conforto". Tais aspectos também são ressaltados por nãodesigners, que mencionaram: "forma e função", "detalhes de um produto", "funcional", "melhorias físicas", "confortável".

Os aspectos estéticos envolvem temas relacionados à aparência do produto e à maneira como eles são percebidos. Entre os designers surgiram palavras como "beleza", "estética", "elegância", "estilo", "cores". Essas palavras são de certa maneira próximas às palavras ressaltadas por não-designers: "formas diferenciadas", "belo, arrojado", "beleza e estilo", "(coisas) bonitas", "forma e/ou aparência", "atraente", "(algo) atrativo".

As qualidades simbólicas referem-se aos temas de valor associados ao produto. $\mathrm{Na}$ fala dos designers aparece o termo "valor", "estilo para algo"; e entre os nãodesigners as palavras "novo" e "bem posicionado". 
De forma geral, tais acepções explicam-se também sob a tríade valor-formafunção, o primeiro elemento sendo associado ao cumprimento da função objetiva do artefato, bem como a elementos intangíveis, tais como os estéticos e simbólicos. 0 segundo e o terceiro elementos aparecem de forma recursiva, indicando alinhamento de visão entre designers e não-designers. Em particular, percebe-se uma emergência de elementos associados pelos não-designers à noção de "novo" ou "arrojado"/"bonito", remetendo a um questionamento sobre a existência de maior ênfase a elementos relacionados à aparência neste grupo.

\subsection{Definindo o design por seus efeitos/contextos}

Esta categoria abrange aspectos das definições que descrevem os efeitos gerais do design, aquilo que a atividade de alguma forma provoca, bem como os contextos em que atua, aquilo que a interessa. Destacamos aqui duas subcategorias, uma delas abrange aspectos de Caráter Generalista, que envolve ideias de ubiquidade, onipresença, ou totalidade; a outra, os Focos do design, que reúne aspectos aos quais o designer volta-se ao desempenhar sua atividade.

Em relação as definições de Caráter Generalista, destacam-se ideias como "está em toda parte", "tudo", "obter o melhor", manifestadas por designers; e trechos como "expressar tudo", "adequação à visão de mundo", de definições de não-designers.

Sobre o Foco Específico, as falas dos designers sugerem direcionar-se o design para: "sociedade", "pessoas", "usuário", "produto", "forma comercial", "relação dos homens com as coisas". Entre os não-designers expressa-se ideias que destacam a importância das necessidades do "consumidor", dos novos "produtos", das "pessoas", do "ambiente", da "sociedade", do "cliente" e do "público-alvo".

\section{Discussão}

Num primeiro olhar as definições sugerem grande semelhança. Afinal, organizam-se elas sob o mesmo regime de separação de categorias e subcategorias. Assim, se elas se acomodaram devidamente nos mesmos espaços é por que algum tipo de analogia foi diagnosticado. Tal asserção é de alguma forma contrária à ideia apresentada anteriormente de que o público geral costuma apresentar níveis baixos de compreensão sobre certos tópicos relacionados à tecnologia (Miller, 2000) ou, mais precisamente, de que não-designers não sabem o que é design: não conhecem os valores, as práticas, as competências, ou tudo o que está por trás do design (Meyer, 2011). Apesar desse aparente conflito entre alguns estudos anteriores e o presente artigo, é necessário enfatizar que as semelhanças aqui apontadas somente representam igualdade na estrutura semântica das definições (que define a separação das categorias). Agora, estreitando o olhar sobre as unidades de análise que preenchem essas categorias e subcategorias, certas distinções serão percebidas.

Uma delas refere-se à precisão com que os respondentes descrevem a atividade. As definições acomodadas na subcategoria Uso de Instrumento/método, por exemplo, dá mostras desse distanciamento. Enquanto os não-designers mencionam palavras de natureza mais imprecisa e fragmentada, tais como "modelo", "desenho" e "pesquisa"; os designers utilizam termos mais abrangentes, como "conjunto de processos e metodologias", "métodos e pesquisa aplicados", uso de "ferramentas". Há, portanto certa distinção nas definições no que diz respeito à precisão de seus termos. 
As definições posicionadas sob as propriedades simbólicas dos produtos são menos presente nas falas dos dois grupos. Em parte isso pode se dar pelo fato de os temas referentes à significado deslocarem-se eventualmente da categoria que descreve as qualidades dos produtos para outras categorias. Mesmo assim, a opção de ambos grupos de respondentes, por distanciar o significado dos produtos, é curiosa. Afinal, a noção de construção de significado como aspecto central do design, diz respeito a uma ideia que parece de alguma forma consolidada entre os estudos em design (ver por exemplos a discussão de Cardoso, 1998).

Sobre a categoria Efeitos/Contexto vale salientar a ideia de que o design possa ser caracterizado por seus focos de atuação. São conhecidos os estudos que sugerem uma espécie de progresso do design nesse campo. Cabe aqui destacar a ideia de Virada Semântica de Krippendorff (2006), ou ainda práticas realizadas por escritórios prestigiados, como o IDEO. O primeiro descreve o movimento através do qual as ênfases do design deslocam-se em determinado momento dos objetos técnicos para os humanos. O segundo, ocupa-se do desenvolvimento de métodos e técnicas interessadas no design centrado nos humanos (ver em Brown, 2009 ou na descrição do método utilizado no escritório, IDEO, 2011). Apesar dos informantes desta pesquisa apontar certa variedade entre os focos de interesses do design, não parecem acompanhar o que sugerem os estudos mencionados.

Entre os não-designers, por exemplo, está muito presente a ideia de que o design deve atender aos interesses do consumidor, cliente, público-alvo, termos que não aparecem nas falas dos designers. Os designers de alguma forma substituem esse foco para pessoas, usuário, homem. Tal nuance sugere que os designers posicionam preocupações de natureza comercial em um ponto um pouco mais afastado da atividade do que o fazem os não-designers.

De forma geral, quando se propõem a definir o design, tanto designers quanto não-designers utilizam-se de um esquema de coalescência entre as partes de suas definições. Uma mesma definição foi frequentemente dividida em diversas categorias. Poucas definições descreveram o design pelas vias de uma só categoria, como na definição: "é a apresentação de um produto". Quase sempre as definições são compostas, como mostra esta definição cujas unidades foram distribuídas em 5 categorias conjuntas: "Design é um método (1) de resolver problemas (2) do mundo prático (3), ajudando a criar ambientes, objetos, produtos, eventos, (4) que contribuam para a vida de pessoas, empresas, instituições, e da sociedade em geral $(5)$ ".

As discussões que podem ser construídas pelas falas dos informantes não devem ser encerradas aqui. O material coletado é farto e permite muitas leituras. Além disso, vale destacar que os resultados aqui apresentados são parte de um dado projeto de pesquisa de maior abrangência, que busca discutir amplamente a imagem social do design. Deve ser pensado, portanto, na perspectiva de uma investigação exploratória e não conclusiva ou exaustiva.

\section{Agradecimentos}

Agradecimento à toda equipe do Grupo de Estudos que trabalhou nesta pesquisa (alunos, bolsistas, colaboradores), tanto nas atividades de discussão e elaboração do artigo, quanto nas tarefas práticas de coleta e análise de dados. 


\section{Referências}

ABRIC, J. C. O estudo experimental das representações sociais. In: JODELET, D. (Org.). As representações sociais. Rio de Janeiro: EdUERJ,. p. 155-171, 2001.

Brown, T. Change by design: How design thinking transforms organizations and inspires innovation (1st ed.). New York: Harper Business, 2009.

CARDOSO, Rafael. Uma introdução à história do design. 3. ed. São Paulo: E. Blucher, 2008.

CASTELLS, M. A sociedade em rede. São Paulo: Paz e Terra, 2009.

Chandrasegaran, S. K., Ramani, K., Sriram, R. D., Horváth, I., Bernard, A., Harik, R. F., \& Gao, W.. The evolution, challenges, and future of knowledge representation in product design systems. Computer-Aided Design, 45(2), 204-228, 2013.

Christidou, V.; Dimopoulos K., Koulaidis V.. "Constructing Social Representations of Science and Technology: The Role of Metaphors in the Press and the Popular Scientific Magazines." Public Understanding of Science 13. 347-62, 2004.

CROSS, N. Design Research: a disciplined conversation. In: Design Issues v.12. n 2, MIT: Cambridge, 1999.

Eurobarometer. Europeans, Science and Technology. Brussels: European Commission DG Research, 2001.

Farr, R.M. "Common Sense, Science and Social Representations." Public Understanding of Science 2:189-204, 1993.

FORTY, A.. Objetos de desejo: design e sociedade desde 1750. São Paulo: Cosac \& Naify, 2007.

FLUSSER, V. O mundo codificado. Por uma Filosofia do design e da comunicação. 1ạ ed. São Paulo: Cosac Naify, 2007.

Friedman, K.. Theory construction in design research: criteria: approaches, and methods. Design Studies, 24(6), 507-522, 2003.

Hjelm, S.I.. If everything is design, what then is a designer? In the Making, [1st] Nordic

Design Research Conference, 29-31, 2005.

<http://www.tii.se/reform/inthemaking/proceedings.htm> (Retrieved June 2005)

IDEO. Human centered design: Toolkit. IDEO, 2011.

JODELET,D.(org.). As Representações sociais. Rio de Janeiro: Eduerj, 2001.

Meyer, G. Quem os designers pensam que são? notas de um discurso profissional. Revista D (Uniritter), v. n. 3, p. 31-48, 2011.

Miller, J.D. The Public Understanding of Science and Technology in the United States: A Report to the National Science Foundation, Science and Technology Indicators. Washington, DC: National Science Foundation, 2000.

KRIPPENDORFF, K. The semantic turn. A new foundation for design. Boca-Raton: Taylor \& Francis, Seções 1.2 (p.5-13), 2006.

. Content Analysis: An Introduction to Its Methodology (3 rd Ed.).

Thousand Oaks, CA: Sage, 2013.

MORAES, R. Análise de conteúdo. Revista Educação, Porto Alegre, v. 22, n. 37, p. 7-32, 1999.

MOSCOVICI, S. Das representações coletivas às representações sociais: elementos para uma história. In: JODELET, D. (Org.). As representações sociais. Rio de Janeiro: EdUERJ, p. 45-66, 2001.

MOSCOVICI, S. Representações sociais: investigações em psicologia social. Petrópolis: Vozes, 2003. 
Roozenburg, N.F.M., Eekels, J.. Product design: fundamentals and methods. John Wiley \& Sons, Chichester, 1995.

Simon, H. A.. The sciences of the artificial (3rd ed) MIT Press, Cambridge, MA, 1996. Schön. The reflective practitioner. How professionals think in action. Basic Books, New York, 1983.

ZURLO, F. Design Strategico, in AA. VV., Gli Spazi e le Arti, vol. IV, n. XXI. Secolo, Editore Enciclopedia Treccani: Roma, 2010. 